\title{
A FaCuldade da Linguagem E os Sistemas de Interface: As Relações entre a Sintaxe e a Semântica*
}

\author{
(The Language Faculty and the Interface Systems: Interactions \\ between Syntax and Semantics)
}

\author{
Esmeralda Vailati Negrão \\ (USP - Universidade de São Paulo/CNPq)
}

\begin{abstract}
This article claims that substantive minimalism, as assumed by Chomsky in the recent developments of the Generative Syntax program, opens a new perspective for the treatment of the Syntax-Semantics Interface. We first characterize the scientific view supporting the Generative model of grammar. The movement metaphor, proposed in order to capture the property observed in human languages that some constituents seem to occupy two different positions in the sentence structure at the same time, reveals that the conceptual-intentional system of the human mind distinguishes among different kinds of semantic relations marked by different mechanisms in the Syntax.

KEY-WORDS: minimalist program; syntax-semantics interface; logical form; distributivity.
\end{abstract}

RESUMO: Este artigo defende a tese de que o minimalismo substantivo assumido por Chomsky nos desenvolvimentos recentes do programa de pesquisa em Sintaxe Gerativa abre uma perspectiva interessante para o tratamento das relações entre a sintaxe e a semântica. A concepşão de ciência adotada na história desse projeto norteou a formulação de um modelo de gramática no qual a propriedade do deslocamento de constituintes tem papel central. O estudo das características dessa propriedade demonstra que os sistemas concepto-intencionais da mente humana distinguem entre diferentes tipos de relações semânticas e impõem exigências sobre o modo como essas relações são marcadas na sintaxe. PALAVRAS-CHAVE: programa minimalista; interface sintaxe-semântica; forma lógica; distributividade.

\footnotetext{
Este artigo é uma versão revista da prova didática apresentada em Concurso de Titular junto ao Departamento de Lingüística da Faculdade de Filosofia, Letras e Ciências Humanas da Universidade de São Paulo, perante banca composta por professores titulares de outras universidades, entre eles a Profa. Lucia Lobato, que muito me honrou com sua participação e a quem eu dedico este trabalho.
}

D.E.L.T.A., 23:esp., 2007 (43-64) 


\section{O projeto gerativo: uma breve incursão na sua concepção de ciência}

Uma das propriedades da linguagem humana, talvez a mais central, consiste no fato de ela possibilitar um uso infinito de meios finitos e discretos. Essa propriedade, que intrigou filósofos e cientistas, e que foi considerada por Galileu como a grande invenção humana, transformou-se em objeto de estudo da ciência lingüística moderna, recebendo tratamentos diferentes, dependendo da teoria.

Noam Chomsky, um dos lingüistas que tomou essa propriedade como central para a construção de sua teoria, assim caracteriza tal propriedade, a partir de uma visão cartesiana:

Humans are only 'incited and inclined' to act in certain ways, not 'compelled' (or random),
and in this respect are unlike machines - that is, the rest of the world. The most striking
example for the Cartesians was the normal use of language: humans can express their thoughts
in novel and limitless ways that are constrained by bodily state but not determined by it,
appropriate to situations but not caused by them, and that evoke in others thoughts that they
could have expressed in similar ways - what we may call 'the creative aspect of language use.
(Chomsky 2002: 66)

Os humanos são somente incitados ou influenciados a agir de certa maneira, não constrangidos (ou levados pelo acaso), e nesse sentido são diferentes das máquinas - isto é, do resto do mundo. $O$ exemplo mais espantoso para os Cartesianos era o uso normal da linguagem: humanos podem exprimir seus pensamentos de maneiras novas e ilimitadas, que são reguladas pelo corpo mas não determinadas por ele, apropriadas a situações mas não causadas por elas, e que suscitam no outro pensamentos que este, por sua vez, poderia ter expressado de maneira semelhante - (isto é) o que podemos chamar de o 'aspecto criativo do uso da linguagem humana'.

O aspecto criativo se revela não só no uso ilimitado, mas também na capacidade que os seres humanos têm de produzir e compreender, sem esforço, expressões nunca antes ouvidas. Descrever e explicitar os mecanismos explicativos dessa capacidade criativa é o objetivo do projeto de pesquisa desenvolvido ao longo dos últimos cinqüenta anos por lingüistas trabalhando no que ficou conhecido como o modelo gerativo de gramática, liderado por Chomsky.

Milner (2002) aponta o papel histórico de Chomsky em relação ao paradigma estruturalista como sendo o de fazer vir à luz três desequilíbrios, ou melhor, três contradições deste último paradigma. Apresentarei aqui 
dois deles e deixarei o terceiro de lado por não ser diretamente pertinente ao tema em discussão.

O primeiro desequilíbrio diz respeito ao fato de que o estruturalismo, assumindo-se implicitamente como uma ciência galileana, da qual a matematização é uma característica definidora, acaba por mascarar uma dematematização, uma vez que nenhum dos procedimentos da lingüística estrutural que lhe conferem um estatuto científico, tais como, a comutação, a distribuição complementar, a distintividade, entre outros, se deixaram traduzir num formalismo lógico-matemático reconhecido como tal. Chomsky propõe um novo modelo lógico-matemático, ao mesmo tempo gerativo e transformacional, capaz de representar adequadamente propriedades da sintaxe das línguas naturais até então não representadas, como a de que a linguagem humana envolve funções gerativas recursivas. Uma outra propriedade central da linguagem humana, também é apontada por Milner (1989) como tendo sido posta à luz pela adoção de um modelo transformacional: os paradoxos posicionais. Uma vez que as sentenças têm uma organização hierárquica na qual os itens lexicais ocupam posições nessa estrutura, é necessário distinguir entre as propriedades das posições e as propriedades desses itens.

A segunda contradição diz respeito à própria concepção geral de ciência. Apoiando-se em um modelo de ciência ideal, o programa estruturalista resultou muito conservador porque assumiu que, para ser uma ciência, a Lingüística deveria satisfazer a certas condições formais como unicidade e especificidade do objeto, e minimalismo de axiomas e de conceitos fundamentais. Está aí, ainda de acordo com Milner, o germe da segunda contradição, porque uma ciência galileana não tem que respeitar o modelo minimalista, uma vez que, cito Milner "uma ciência galileana, por definição, é uma teoria empírica. O minimalismo epistemológico é radicalmente antigalileano" (Milner, 2002: 222). Para esse autor, um outro modelo ideal para uma ciência galileana é aumentar o seu conteúdo empírico para assim aumentar o seu grau de refutabilidade.

Ainda segundo Milner, Chomsky, em seu livro Aspects of the Theory of Syntax publicado em 1965, adota uma concepção de ciência baseada em uma epistemologia antiminimalista, opondo-se frontalmente aos epistemólogos empiristas. Milner cita uma passagem de Aspects para corroborar sua conclusão. Passo, então, a uma citação ampliada do trecho de Chomsky escolhido por Milner: 
It is, for the present, impossible to formulate an assumption about initial, innate structures rich enough to account for the fact that grammatical knowledge is attained on the basis of the evidence available to the learner. Consequently, the empiricist effort to show how the assumptions about a language-acquisition device can be reduced to a conceptual minimum is quite misplaced. The real problem is that of developing a hypothesis about initial structure that is sufficiently rich to account for acquisition of language, yet not so rich as to be inconsistent with the known diversity of language. (Chomsky, 1965:58)

No presente, é impossivel formular uma hipótese sobre as estruturas inatas iniciais ricas o suficiente para dar conta do fato de que o conbecimento gramatical é atingido com base na evidência disponível para o aprendiz. Conseqüentemente, o esforço empirista de mostrar como tal hipótese sobre um dispositivo de aquisição de linguagem pode ser reduzido a um mínimo conceitual está bem mal colocado. O problema real é o de desenvolver uma hipótese sobre a estrutura inicial que seja rica o suficiente para dar conta da aquisiz̧ão da linguagem, ainda que não tão rica a ponto de ser inconsistente com a conbecida diversidade da linguagem.

\section{Milner (2002: 229) conclui:}

Chomsky remettait en cause, d'un seul movement, toutes les formes de structuralisme, qu'íl s'agît de la linguistique stricto sensu, des disciplines traitant des objets non langagiers ou même du croisement accompli par Althusser entre structuralisme et marxisme. Double conclusion, là encore: d'une part, il est affirmé que le minimalisme épistemologique est radicalement antigaliléen, puisqu'il vide de tout contenu le caractère empirique des sciences galiléenes; d'autre part, il est affirmé que la linguistique peut s'écarter de l'ideal minimaliste et construire des systèmes d'hypothèses à la fois nombreuses et refutables.

Chomsky põe em questão, com um só movimento, todas as formas de estruturalismo, quer tratese da lingü̈́stica stricto sensu, quer das disciplinas que se dedicam aos objetos não propriamente lingüísticos ou mesmo do cruzamento, feito por Althusser, entre estruturalismo e marxismo. Aí, uma dupla conclusão: de um lado ele afirmou que o minimalismo epistemológico é radicalmente antigalileano, uma vez que ele esvazia as ciências galileanas de todo seu conteúdo empírico; por outro lado, ele afirmou que a lingüística pode se distanciar do ideal minimalista e construir sistemas de hipóteses ao mesmo tempo numerosos e refutáveis.

Para aqueles dentre nós que acompanham o desenvolvimento do projeto gerativo, essa afirmação de Milner causa no mínimo surpresa. Cabe aqui um comentário. Quero lembrar que as reflexões de Milner sobre o gerativismo tomam como referência o desenvolvimento do projeto desde seu início até o momento da transição entre o que é conhecido como modelo padrão estendido e o modelo de regência e vinculação, que resultou na proposta de Princípios e Parâmetros e, talvez, isso explique tal afirmação. 
Entretanto, a passagem de Aspects citada acima, ao remeter-nos à concepção central da natureza da investigação levada à frente pela Teoria Gerativa, já revela um conflito inerente a essa concepção. A questão é caracterizar o que é esse conhecimento lingüístico que todos os falantes de uma língua possuem e oferecer uma resposta para o que ficou conhecido como o problema de Platão: Como é que esse conhecimento lingüístico, altamente articulado e rico é adquirido, tão rapidamente e tão cedo em nossas vidas, se os dados a que somos expostos são tão pobres? A hipótese explicativa oferecida é a de que a linguagem é um objeto natural, um componente da mente humana, biologicamente determinada pela dotação genética da espécie. A postulação dessa hipótese explicativa nos leva a assumir que o estado cognitivo inicial já seja um sistema estruturado. A teoria sobre esse estado cognitivo inicial é chamada de Gramática Universal. A concepção de linguagem apresentada representa uma mudança de foco no objeto de estudo da lingüística: agora nosso objeto são os sistemas mentais de representação e computação. Portanto, a tarefa central é caracterizar os elementos básicos dessa língua interna. No entanto, se por um lado é necessário mostrar que os mecanismos disponibilizados pela Gramática Universal são ricos o suficiente para dar conta da variedade de línguas faladas no mundo e, portanto, adequados para a tarefa da descrição das diversas línguas, por outro, é necessário mostrar que esses mecanismos são mínimos o suficiente para explicar a aquisição da linguagem pela criança. Daí o conflito.

No modelo gerativo-transformacional de Aspects, a ânsia pela adequação empírica fez com que a busca pela construção de uma gramática mínima ficasse adormecida. $\mathrm{O}$ tratamento descritivo adequado da sintaxe das diversas línguas naturais levou à construção de um modelo de gramática que continha um imenso sistema de regras, específicas praticamente para cada construção de cada língua. A complexidade desse sistema entrava em contradição com o que é chamado de o problema lógico da aquisição, qual seja, a idéia de que a criança adquirindo uma língua não tem acesso a um sistema de dados tão complexo. Mais ainda, a idéia de que um sistema tão complexo não pode ser adquirido tão rapidamente e sem estimulação compatível.

Em entrevista publicada no livro On nature and language (Chomsky, 2002), concedida a Belletti \& Rizzi por ocasião de sua visita à Universidade de Siena em 1999, Chomsky avalia, vinte anos depois, o papel dos 


\section{seminários de Pisa, conhecidos como The Pisa Lectures, que tiveram um forte impacto sobre o programa de pesquisa gerativista:}

... so there is kind of a contradiction, or at least a tension, a strong tension between the effort to give a descriptively adequate account and to account for the acquisition of the system, what has been called explanatory adequacy. Already in the 1950s it was clear that there was a problem and there were many efforts to deal with it; the obvious way was to try to show that the diversity of rules is superficial, that you can find very general principles that all rules adhere to, and if you abstract those principles from the rules and attribute them to the genetic endowment of the child then the system that remain look much simpler. That is the research strategy. (...) What happenned at Pisa is that somehow all this work came together for the first time in the seminars, and a method arose for sort of cutting the Gordian knot completely: namely eliminate rules and eliminate constructions altogether. So you don't have complex rules for complex constructions because there aren't any rules and there aren't any constructions. There is no such thing as the VP in Japanese or the relative clause in Hungarian. Rather, there are just extremely general principles like 'move anything anywhere' under fixed conditions that were proposed, and then there are options that have to be fixed, parametric choices: so the head of the construction first or last, null subject or not a null subject, and so on. Within this framework of fixed principles and options to be selected, the rules and the constructions disappear, they become artifacts. (p.93-94)

...então bá um tipo de contradição, ou pelo menos, uma forte tensão entre o esforço de dar um tratamento descritivo adequado aos dados lingüísticos e uma explicação para a aquisiz̧ão do sistema, chamada de adequação explicativa. Já nos anos 50 estava claro que havia um problema e que havia muitos esforços para tratar dele; a maneira óbvia era tentar mostrar que a diversidade de regras é superficial, que se pode achar um conjunto de princípios bem gerais a que todas as regras possam se adequar e que, abstraindo-se tais princípios das regras e atribuindo-os à dotação genética da criança, o sistema resultante passa a ser, então, muito simples. Essa foi a estratégia de pesquisa adotada. (...) O que aconteceu em Pisa é que, de alguma maneira, o quadro se fechou pela primeira vez naquele seminário, e um método surgiu para cortar o nó górdio: qual seja, eliminar regras e eliminar construções de uma vez. Portanto, não há regras complexas para construções complexas porque simplesmente não há regras e não há construções. Coisas como o Sintagma Verbal do japonês ou a oração relativa do húngaro não existem. O que existe são, de um lado, princípios gerais como 'mova qualquer coisa para qualquer posição', que devem respeitar condiç̃̃es fixas, e, de outro, opções que precisam ser fixadas, parâmetros: como o núcleo de uma construção é realizado no início ou no fim do sintagma, sujeito vazio ou sujeito preenchido, e assim por diante. Neste modelo de princípios fixos e de opções paramétricas, as regras e as construções desapareceram. Elas se tornaram meros artefatos descritivos.

Essa foi a estratégia de pesquisa adotada pelo projeto gerativo no modelo conhecido como o de Princípios e Parâmetros. O avanço que ela deu 
para o conhecimento sobre os princípios que integram as gramáticas das diversas línguas naturais foi espantoso. Pode-se dizer com Chomsky que ela produziu "um rico corpo de doutrina" que, por sua vez, permitiu que concepções galileanas fossem reintroduzidas na agenda de pesquisa do projeto. Chomsky usa a expressão "estilo galileano" para a concepção metodológica segundo a qual são os modelos construídos que devem ser tomados como verdade, uma vez que o mundo sensível dilui, num conjunto mais diversificado e não hierarquizado de informações, as propriedades pertinentes ao modo de operação de um certo fenômeno.

Na conferência intitulada Perspectives on Language and Mind, Chomsky (2002) retoma o próprio Galileu para explicitar essa concepção:

Similar conceptions, now emerging in a certain form in the study of language, also had a central place in Galileo's thought. In studying acceleration, he wrote, 'we have been guided...by our insight into the character and properties of nature's other works, in which nature generally employs only the least elaborate, the simplest and easiest of means. For I do not believe that anybody could imagine that swimming or flying could be accomplished in a simpler or easier way than that which fish and birds actually use by natural instinct.' (...) Galileo was guided by the ontological principle that 'Nature is perfect and simple and creates nothing in vain,' bistorian of science Pietro Redondi observes. (p. 57)

Concep̧ões similares, agora vindo à tona, de uma certa maneira, nos estudos sobre a linguagem, também tiveram um papel central no pensamento de Galileu. Estudando a aceleração, ele escreveu, 'nós temos sido guiados...por nosso insight sobre o caráter e as propriedades de outros trabalhos da natureza, nos quais geralmente ela emprega somente os meios menos elaborados, mais simples e fáceis. Porque eu não acredito que alguém possa imaginar que o nadar e o voar possam ser executados de maneira mais simples e fácil do que aquela que os peixes e os pássaros de fato utilizam por instinto natural' (...) Galileu foi guiado pelo princípio ontológico de que a Natureza é perfeita e simples e não cria nada em vão,' observa o historiador da ciência Pietro Redondi.

A etapa mais recente do projeto gerativo, chamada de Programa Minimalista, assume a concepção metodológica do 'estilo galileano'. O minimalismo metodológico consiste na busca de inteligibilidade e simplicidade para a teoria proposta.

Por outro lado, a citação de Galileu traz também uma nova questão, de cunho substantivo, introduzida no programa de investigação em curso: o da natureza perfeita do nosso objeto de estudo, a linguagem humana.

Lopes (2003), retomando Chomsky (1998), assim resume o contraste estabelecido, no programa de pesquisa em discussão, entre minimalismo 
metodológico, tomado como sua versão fraca, e minimalismo ontológico, tomado como sua versão forte, (substantivo, em nossos termos):

A versão fraca baseia-se em Ocam's razor e é o que Uriagereka (1999) chama de minimalismo "metodológico", pois busca a forma mais otimizada de teorizar; em poucas palavras, quanto menos melhor: um axioma é melhor que dois, um algoritmo é melhor que dois etc. A versão forte, batizada por ele de minimalismo "ontológico", não considera quão ótima é a teoria sobre a Faculdade da Linguagem, mas quão ótima é a Faculdade da Linguagem propriamente. (p. 152)

\section{Perfeição e imperfeição: a relação entre o componente computacional (sintaxe) e as interfaces}

O projeto gerativo entende por minimalismo substantivo a busca de determinar se o próprio objeto da Lingüística, ou seja a linguagem humana, tem uma arquitetura perfeita. Essa busca inspira-se na concepção de que a natureza é perfeita, como visto na citação de Galileu acima, concepção esta que tem permeado investigações sobre o mundo biológico.

A adoção dessa hipótese pelo programa de pesquisa gerativo instaura, nos estudos sobre a sintaxe, uma nova ótica que vem exigindo não só uma revisão geral do modelo de gramática concebido, mas também uma reanálise dos fenômenos cuja explicação por princípios gerais tinha encontrado uma certa estabilidade. Essa nova ótica tem conseqüências importantes para o tratamento das relações entre a sintaxe e a semântica, tema deste artigo.

Cabe, porém, em primeiro lugar, compreender melhor o significado da hipótese sobre a arquitetura perfeita da linguagem. Adjetivos como bom, perfeito, apresentam a propriedade de serem relacionais, o que exige, portanto, a explicitação de seu termo de comparação: se a arquitetura é perfeita, ela é perfeita em relação a quê? O senso comum, sobre qual a função da linguagem, poderia apontar para uma resposta envolvendo propriedades que propiciem uma melhor comunicação entre os seres humanos. No entanto, a mais rudimentar análise da linguagem humana já apontaria nela propriedades que refutariam tal hipótese, tais como: ambigüidades, subentendidos, redundância, só para citar algumas.

No Programa Minimalista, a pesquisa visa a investigar como deveria ser a gramática das línguas naturais a fim de que ela possa prover as infor- 
mações necessárias para os demais componentes da mente humana, externos à faculdade da linguagem. Nas palavras de Chomsky (2002: 108):

The language faculty has to interact with those systems, otherwise it's not usable at all. So, we may ask: is it well designed for the interaction with those systems? Then you get a different set of conditions. And in fact the only condition that emerges clearly is that, given that the language is essentially an information system, the information it stores must be accessible to those systems, that's the only condition. We can ask whether language is well designed to meet the condition of accessibility to the systems in which it is embedded.

A faculdade da linguagem tem que interagir com esses sistemas, senão ela não tem finalidade. Então podemos perguntar: ela é bem projetada para a interação com esses sistemas? Assim se obtém um conjunto de condições diferentes. E, de fato, a única condição que emerge claramente é a de que, dado que a linguagem é essencialmente um sistema de informação, a informação que ela armazena precisa estar acessível a esses sistemas, essa é a única condição. Pode-se perguntar, então, se a linguagem foi bem projetada para satisfazer essa condição de acessibilidade pelos sistemas nos quais ela se encaixa.

Nessa perspectiva, o modelo de gramática proposto para dar conta da capacidade humana para a linguagem segue a seguinte arquitetura: 1) um léxico ou dicionário da língua no qual estariam contidos todos os itens lexicais, acompanhados de traços carregando especificações com relação à sua face fonológica e semântica, além de informações pertinentes sobre como tais itens participam da estruturação sintática; 2) um componente computacional em que itens lexicais se combinam. A formação de uma sentença não resulta da combinação aleatória desses itens. Muito pelo contrário, as sentenças das línguas naturais seguem um padrão fixo de combinação, resultante da operação sintática de concatenação de constituintes. De maneira bem simplista, podemos caracterizar a estrutura básica das sentenças como um processo recursivo de encaixamento de sintagmas. $\mathrm{O}$ componente computacional usa os itens lexicais para gerar descrições estruturais das sentenças formadas, ou seja, resultam desse processo de computação um par de representações, caracterizadas como representações dos níveis de interface uma vez que elas fornecem as informações lingüísticas pertinentes para outros sistemas cognitivos. Os sistemas cognitivos tributários dos níveis de interface são chamados sistemas de desempenho, responsáveis por nossos pensamentos e ações, neles incluídos a articulação dos sons, a interpretação, a expressão de crenças e desejos, reunidos em dois tipos: os sistemas sensório-motores e os sistemas concepto-intencionais. Os sistemas sensório-motores têm acesso a um dos níveis de interface, 
a Forma Fonológica, ao passo que os sistemas concepto-intencionais têm acesso ao nível de representação conhecido como Forma Lógica.

A representação da estrutura sentencial em Forma Lógica, gerada pelo componente computacional por meio da concatenação dos itens lexicais, deve conter as informações gramaticais pertinentes para a interpretação semântica.

Acontece que nem todas as informações gramaticais, já trazidas pelos itens lexicais do Léxico, sob a forma de traços, podem ser interpretadas pelos sistemas concepto-intencionais. Um exemplo são as marcas morfológicas que desempenham um papel interno à gramática, como a marca morfológica de concordância de pessoa e de número no verbo. O seu papel é marcar uma relação sintática que se estabelece entre o sujeito e o predicado de uma sentença em algumas línguas. $\mathrm{Na}$ perspectiva adotada pelo programa de pesquisa em discussão, essa marcação morfológica parece representar uma imperfeição, uma vez que essa concordância não expressa uma informação pertinente para as interfaces. Essa observação evidencia a necessidade do estabelecimento de uma distinção entre os tipos de traços morfológicos carregados pelos itens lexicais: os traços não interpretáveis, que carregam informações pertinentes somente para o componente computacional, e os traços interpretáveis, que carregam informações relevantes para os outros sistemas da mente. A marcação morfológica de plural nos substantivos é um exemplo de um traço interpretável, porque pluralidade no nome é um traço que carrega informação pertinente para a interpretação semântica, uma vez que o sistema concepto-intencional distingue entidades de conjunto de entidades.

A hipótese da arquitetura perfeita abre a possibilidade de uma nova compreensão do papel que a Morfologia desempenha na organização das línguas humanas. O fato de os traços morfológicos não interpretáveis não serem legíveis pelas interfaces torna a sua eliminação necessária no decorrer da derivação das expressões lingüísticas. Essa eliminação dá-se por um mecanismo de checagem, que consiste no apagamento de traços não interpretáveis quando um constituinte, portador de tais traços, se move para uma posição na estrutura sentencial a partir da qual ele pode contrair relações com uma categoria portadora de traço compatível para a checagem e conseqüente apagamento de tais traços. 
Sendo assim, o deslocamento de constituintes, uma propriedade caracterizadora das línguas humanas que capta a observação de que os constituintes se realizam nas sentenças em posições diferentes daquelas que parecem ocupar para ser compatível com a interpretação a eles atribuída, passa a ser, nessa perspectiva, evidência para a arquitetura perfeita da linguagem. Essa é uma ótima solução para o que Milner caracterizou como paradoxo posicional. Um exemplo pode ajudar na compreensão desse paradoxo. Na sentença:

(1) O que a Maria trouxe para a festa?

embora o constituinte "o que" seja realizado no início da sentença para marcar o seu sentido interrogativo, ele é interpretado como aquilo que foi trazido, ou seja, o complemento de trazer, que em sentenças afirmativas realiza-se em adjacência ao verbo como em:

(2) A Maria trouxe flores para a festa

'O que' e 'flores', ambos complementos do verbo trazer mantendo com ele a mesma relação semântica de objeto trazido, realizam-se em posições diferentes nas sentenças acima.

A propriedade do deslocamento, uma propriedade sintática, parece apontar para o fato de que os sistemas concepto-intencionais distinguem entre diferentes tipos de relações semânticas e impõem exigências sobre o modo como essas relações são marcadas na sintaxe: relações semânticas estabelecidas entre um predicado e seus argumentos, como as relações temáticas de agente, paciente, causa, são marcadas localmente; relações discursivas denotadoras do papel informacional dos constituintes, como as de tópico, foco, especificidade, são marcadas, configuracionalmente, pela realização desses constituintes na periferia esquerda das sentenças; relações de escopo envolvendo sintagmas quantificados e operadores são marcadas por movimento coberto em Forma Lógica, ou seja, na etapa da derivação depois da aplicação da operação de Spell-out, operação esta que alimenta a outra interface do componente computacional, a Forma Fonológica. O deslocamento pode, assim, ser considerado uma solução perfeita para o problema de que esses diferentes tipos de informação semântica precisam estar conectados. Fazer o mapeamento rigoroso das configurações sintáticas associadas a interpretações semânticas específicas passa a ser de extrema importância para que se possa determinar com mais clareza essa 
retroalimentação entre o sistema computacional e a sua interface com os sistemas cognitivos conceptuais externos à faculdade da linguagem.

\section{Forma lógica e distributividade}

Estudos que se debruçaram sobre os fenômenos de escopo ${ }^{1}$ envolvendo sintagmas quantificados e operadores têm uma longa história no projeto gerativo (Huang, 1982; May,1985; Aoun \& Li, 1993; Hornstein, 1995; Beghelli \& Stowell, 1997, entre outros). Analisando dados lingüísticos exemplificadores da correlação entre a interpretação atribuída a sentenças contendo sintagmas quantificados e a posição por eles ocupada na estrutura sentencial, esses autores argumentam em favor da postulação do nível de interface Forma Lógica e sustentam que esses dados são evidência para um tratamento sintático das relações de escopo.

Para o tratamento sintático dos fenômenos de escopo, parte-se da idéia de que o escopo de um sintagma quantificado é determinado pelo fato de que esse sintagma se move, em Forma Lógica, para uma posição fora da sentença, ou na periferia esquerda da sentença, hierarquicamente superior, de onde ele c-comanda o domínio sobre o qual ele tem escopo. ${ }^{2}$ Uma das motivações para esse tratamento é o fato de que os deslocamentos sintáticos, necessários para a derivação de outras estruturas, também dão conta de explicar as propriedades dos fenômenos de escopo. Mais ainda, podemos observar que movimentos sintáticos interagem com os mecanismos de atribuição de escopo.

Uma evidência dessa interação é a interpretação associada à sentença em (3).

(3) O que muitos alunos leram?

\footnotetext{
1 Ilari \& Geraldi (1987: 33) definem escopo, no âmbito da semântica, como "conjunto de conteúdos semânticos sobre os quais uma operação significativa atua”. Na Teoria Gerativa, escopo foi definido a partir da estrutura hierárquica dos constituintes da sentença. May (1985: 5) dá a seguinte definição:

(i) The scope of a is the set of nodes that $\alpha$ c-commands at LF;

(ii) $\alpha$ c-commands $\beta$ iff the first branching node dominating a dominates $\beta$ (and $\alpha$ does not dominate $\beta$ ).

2 Para a definição de c-comando ver nota 1.
} 
Nela, o deslocamento do sintagma interrogativo, gerado em posição de complemento, para a periferia esquerda da sentença a fim de marcar que se trata de uma sentença interrogativa, acarreta uma inversão nas relações de escopo entre o sintagma interrogativo deslocado 'o que' e o sintagma quantificado 'muitos alunos', em posição de sujeito.

O fenômeno do escopo relativo advindo da interação entre sintagmas quantificados e/ou operadores numa dada sentença torna-se visível através das possíveis interpretações associadas com as sentenças nas quais eles se inserem. Um dos tipos de interpretação elucidativos das relações de escopo é a interpretação distributiva, que pode ser parafraseada da seguinte maneira: "para cada um dos membros, a,b,c... do conjunto introduzido pelo sintagma quantificado, existem eventos distintos, ou grupos distintos introduzidos por um outro sintagma quantificado, que estão associados com a,b,c... respectivamente". A possibilidade de uma resposta individual, não distributiva, à pergunta em (3): “_O novo livro de Chomsky”, é evidência de que o deslocamento do sintagma interrogativo fez com que ele tivesse o sintagma quantificado sujeito 'muitos alunos' sob seu escopo, inibindo a possibilidade de uma leitura distributiva de 'muitos alunos' sobre 'o que'. Mesmo ocupando uma posição hierárquica superior a 'muitos alunos', 'o que' mantém a interpretação temática associada ao complemento do verbo ler.

Negrão, em um conjunto de trabalhos (1997,1999, 2001, 2002), investiga algumas propriedades observadas na distribuição e nas interpretações de sentenças contendo sintagmas quantificados distributivos introduzidos por todo e cada no português brasileiro. Neles, a autora também argumenta em favor de um tratamento sintático para as relações de escopo, em Forma Lógica. Ela fundamenta-se, teoricamente, na teoria Target Landing Site Theory of Scope 'Teoria de Escopo de Aterrissagem Seletiva', proposta por Beghelli (1995) e Beghelli \& Stowell (1997), segundo a qual os sintagmas quantificados não formam uma classe homogênea, ou seja, os diferentes sintagmas quantificados comportam-se de maneira distinta com relação às propriedades de escopo que podem assumir.

As propriedades específicas dos sintagmas distributivos permitem caracterizá-los como integrantes de uma classe distinta, a dos sintagmas quantificados distributivos. Com Beghelli (1995), seguindo Choe (1987), Negrão considera a distributividade como uma relação binária que requer um dis- 
tribuidor, ou seja, um conjunto cujos elementos distribuem-se sobre, ou melhor são pareados a, elementos de um outro conjunto (nos termos de Choe, sorting key e distributed share, respectivamente). O papel de distribuidor vai ser desempenhado pelo conjunto denotado pela restrição do sintagma distributivo introduzido por cada, enquanto que o papel de parte distribuída pode ser desempenhado tanto por um outro sintagma quantificado, normalmente um sintagma contendo um indefinido ou um elemento denotador de cardinalidade, quanto pelo argumento evento associado ao predicado, quantificado existencialmente. Na sentença:

(4) Cada professor preparou uma questão

o distribuidor serão os membros do conjunto denotado por professor e a parte distribuída serão os membros do conjunto denotado por questão.

Davidson (1980), no artigo que pode ser caracterizado como um clássico da literatura semântica, propõe que a forma lógica ${ }^{3}$ adequada para as sentenças de ação precisa ser construída de maneira a expressar a existência de um evento do qual certos indivíduos foram participantes, uma vez que, para ele, o significado das sentenças é construído a partir da contribuição de cada uma de suas partes para a estruturação geral. Sendo assim, a estrutura argumental dos verbos que integram essas sentenças deve conter uma outra posição que abrigue o próprio evento. Ele argumenta que ao introduzir, na forma lógica, os eventos como entidades sobre as quais se pode fazer um número indefinido de afirmações, ele resolve o problema da poliadicidade variável dos verbos de ação. Ele também argumenta que, assim, pode incorporar uma das propostas interessantes da análise de Reichenbach (apud Davidson, 1980) para a forma lógica dessas sentenças, a de que elas contêm um quantificador existencial prendendo uma variável, que na análise de Davidson corresponde ao argumento evento. A título de exemplificação, apresento em (5b), a forma lógica davidsoniana para a sentença $(5 a)$ :

(5) a. Ela comprou toalhas em Maceió

b. $\exists$ e [comprar (toalhas) (ela) (e) \& em (Maceió) (e)]

\footnotetext{
3 Cabe ressaltar que forma lógica nessa passagem tem que ser entendida no sentido que lhe é dado pelos filósofos, qual seja, a de uma expressão da linguagem lógica que capta as propriedades de uma sentença responsáveis por certas inferências. Não se trata aqui do nível de representação da interface entre o componente computacional e os sistemas concepto-intencionais.
} 
Seguindo essa tradição, $\mathrm{B} \& \mathrm{~S}$ assumem que todos os sintagmas verbais contêm uma posição temática de evento preenchida pelo argumento evento do predicado e que, quando não há um sintagma quantificado disponível para funcionar como parte distribuída de um sintagma quantificado distributivo, para assim satisfazer suas exigências de distribuição, é o argumento evento do predicado, quantificado existencialmente, que desempenha tal papel.

Se nos voltarmos agora para alguns dos dados analisados por Negrão e, a partir deles, retomarmos as principais generalizações empíricas postuladas pela autora, poderemos tomá-los como evidência de que os sistemas concepto-intencionais impõem exigências sobre o modo como as relações semânticas são marcadas na sintaxe e que, por outro lado, as representações resultantes da derivação sintática fornecem informações interpretáveis, isto é, desprovidas de conteúdo meramente gramatical, para os sistemas cognitivos da mente humana, tese central deste artigo.

Uma primeira constatação de Negrão é a de que há uma assimetria em aceitabilidade entre sentenças contendo sintagmas quantificados introduzidos por cada ocupando a posição de sujeito, em contraste com as que os contêm ocupando a posição de objeto, como em:

(6) a. Cada aluno leu alguns textos

b. Cada homem ama uma mulher

c. *Alguns alunos leram cada texto

d. *Uma mulher ama cada homem

Essa assimetria é explicada por Negrão como devida a propriedades da estruturação das sentenças do português brasileiro. ${ }^{4}$ Deixo de lado os casos em que, em posição de objeto, os sintagmas quantificados introduzidos por cada são partitivos ou tem um modificador, como uma relativa, acrescentado à sua restrição, porque nesses casos as sentenças são perfeitas.

A segunda constatação é a de que o argumento evento do predicado tem um papel determinante nas possibilidades de realização e de interpretação associadas ao sintagma distributivo introduzido por cada. Contrariamente à posição assumida por $\mathrm{B} \& \mathrm{~S}$, Negrão propõe que o argumento

4 Para maiores detalhes da análise proposta, ver Negrão (1999) e Negrão \& Viotti (2000). 
evento não está presente na estrutura argumental de qualquer predicado. Baseando-se em Kratzer (1995), que argumenta que a diferença entre os predicados chamados de individual level predicates e os chamados stage-level predicates é a de que a estrutura argumental destes últimos, contrariamente à dos primeiros, contém uma posição extra para eventos, que a autora postula ser simplesmente um argumento para localizações espaço-temporais, Negrão conclui que os sintagmas quantificados distributivos introduzidos por cada exigem que o predicado, núcleo da sentença da qual são um constituinte, não só contenha um argumento evento, mas também que a esse argumento seja associada a interpretação de uma seqüência temporal de subeventos que não se sobrepõem. Essa leitura de seqüência de eventos é desencadeada por certas marcas aspecto-temporais da flexão da sentença, por certos tipos de modificação da localização espaço-temporal do evento descrito pela sentença ou por alguns verbos que já trazem no próprio significado lexical a idéia de iteração de subeventos. Os dados e as conclusões de Negrão $(2001,2002)$ são apresentados a seguir.

(7) a. *Cada homem é inteligente

b. *Cada funcionária está grávida

(8) a. *Cada homem é inteligente num período do ano

b. Cada funcionária está grávida num período do ano

Os dados em (7) mostram que tanto sentenças em que o sintagma distributivo introduzido por cada é o sujeito de um predicado individual level, quanto sentenças em que ele é sujeito de um predicado stage level são estranhas. No entanto, se o conteúdo do argumento para localizações espaçotemporais aparecer modificado de maneira explícita, imediatamente o contraste se torna aparente.

As sentenças em (9), a seguir, confirmam essa generalização. Elas contêm um predicado stage level no pretérito perfeito, portanto um predicado cuja estrutura argumental contém um argumento evento. No entanto, enquanto a sentença (9a) é inaceitável, as sentenças (9b\&c) são perfeitas. Em ambas, o veículo em que cada convidado chegará em (9b) e o sintagma denotador da localização temporal em (9c), modificadores do argumento evento, funcionam como parte distribuída para o sintagma quantificado distributivo. 
(9) a. *Cada convidado chegou

b. Cada convidado chegou num carro

c. Pouco a pouco cada convidado chegou

As sentenças de (7) a (9) acima contêm sintagmas quantificados distributivos na posição de sujeito. As sentenças com sintagmas distributivos em posição de objeto também se tornam aceitáveis, se a leitura de seqüência temporal de subeventos for explicitada por marcas aspectuais, verbos que já a trazem em seu próprio significado lexical, ou modificadores da localização espaço-temporal:

(10) a. Alguns alunos têm lido cada texto

b. Os alunos aplaudiram cada conferencista

c. Pouco a pouco alguns alunos leram cada texto

Uma última generalização, esta postulada por Gomes (2004), diz respeito ao fato de que sintagmas distributivos introduzidos por cada são licenciados em posição de objeto, se o nome em sua restrição denotar partes iguais de um todo, o que permitirá que a denotação de todo o sintagma verbal, do qual o sintagma distributivo é um constituinte, seja a de um conjunto de singularidades. O contraste entre as sentenças em (11) exemplifica esta generalização:

(11) a. *Os meninos comeram cada bolo

b. Os meninos comeram cada fatia

Fatia induz-nos à idéia de um conjunto de partes iguais e a interpretação do sintagma verbal é, novamente, a de uma seqüência iterativa de eventos de comer.

Portanto, para que uma sentença contendo um sintagma distributivo introduzido por cada seja aceitável, é necessário que a leitura de seqüência temporal de subeventos que não se sobrepõem, seja desencadeada. O oferecimento de um outro conjunto introduzido por indefinidos ou sintagmas quantificados denotadores de cardinalidade, marcas aspectuais na flexão verbal, verbos que já trazem essa leitura em seu próprio significado lexical, modificadores da localização espaço-temporal do predicado, ou ainda, um complemento introduzido por cada que denote partes de um todo são os 
recursos gramaticais disponíveis no português brasileiro para desencadear tal leitura.

Lasersohn (1995) retoma um conjunto de estudos em lingüística descritiva e diacrônica sobre uma classe de morfemas encontrados em línguas indígenas norte-americanas e línguas do oeste da África, entre outras, às vezes chamados de afixos distributivos, outras vezes de marcadores verbais de pluralidade, que parecem funcionar como um tipo de marcação de plural sobre o verbo. Ele vai chamá-los de marcadores pluracionais, para exatamente distingui-los da marcação plural de concordância do verbo com um argumento plural, por se tratar de um outro tipo de pluralidade verbal. No caso de conterem marcadores de pluracionalidade, o predicado é interpretado como representando a ocorrência de múltiplos eventos. Nos termos da teoria esboçada acima, marca de pluracionalidade seria um traço interpretável, contrariamente ao traço não interpretável de concordância plural.

Lasersohn retoma esses estudos justamente para argumentar em favor de uma análise que introduza a estrutura de eventos no sistema semântico, para explicar fatos do inglês envolvendo coordenação de sintagmas nominais e de outras categorias, modificação adverbial coletiva, e leitura coletiva e distributiva de predicados. Sem entrar na formalização elaborada por esse autor, pode-se dizer, de maneira intuitiva, que a contribuição semântica dos marcadores de pluracionalidade é fazer com que a denotação dos verbos, por eles modificados, seja a de um conjunto não vazio de subeventos do mesmo tipo do evento denotado pelo verbo, em que o transcorrer de tempo de cada subevento não se sobrepõe ao de outro subevento do mesmo conjunto.

Matthewson (2000) mostra que a língua Salish St'at'imcets tem um elemento distributivo que ela também analisa como um marcador de pluracionalidade porque, exatamente como os marcadores de pluracionalidade temporal, a sua presença na sentença desencadeia a interpretação de existência de um conjunto de subeventos temporalmente não sobrepostos. Porém, diferentemente dos marcadores comumente descritos na literatura sobre marcadores de pluracionalidade, ele não só pode aparecer operando sobre o predicado, como também pode ocupar a posição dos quantificadores integrantes de sintagmas nominais quantificados, tanto em posição de sujeito quanto em posição de objeto. 
O comportamento dos sintagmas quantificados distributivos introduzidos por cada analisado acima pode ser reinterpretado a partir das conclusões advindas dos trabalhos que investigam o traço de pluracionalidade dos predicados. Os recursos gramaticais desencadeadores da leitura de seqüência temporal de subeventos que não se sobrepõem, tais como, marcas aspectuais na flexão verbal, verbos que já trazem essa leitura codificada em seu significado lexical, modificadores da localização espaço-temporal do predicado, podem ser agora reanalisados como marcadores de pluracionalidade. Nas sentenças:

(12) a. A aluna grávida tem vindo à aula

b. O menino saltitou sem parar

c. O aluno leu o texto pouco a pouco

a marca aspectual na flexão do verbo (12a), o significado iterativo contido no item lexical (12b) e o modificador temporal pouco a pouco (12c) são as marcas desencadeadoras da interpretação de eventos plurais ${ }^{5}$ das sentenças em (12). Mas o que dizer do contraste entre as sentenças ( $9 a \& b)$ retomadas aqui como (13a\&b), respectivamente:

(13) a. *Cada convidado chegou

b. Cada convidado chegou num carro

Em (13b), contrariamente à sentença (13a), a interpretação de existência de um conjunto de subeventos de chegar em um carro temporalmente não sobrepostos confere gramaticalidade às exigências de distributividade do sintagma quantificado introduzido por cada. No entanto, não há em (13b) nenhum marcador de pluracionalidade. Cada parece, ele mesmo, ser um marcador de pluracionalidade do português, embora distribucionalmente realizado no interior de sintagmas nominais. Para realizar essa marcação ele precisa ocupar uma posição na estrutura sentencial a partir da qual ele possa ter escopo sobre o predicado que ele torna plural (cf. $6 \mathrm{a} \& \mathrm{~b}$ vs. $6 c \& d)$ e assim satisfazer suas exigências de distributividade.

Voltando, agora, para o tema central deste artigo podemos perguntar: o que a análise aqui apresentada nos diz a respeito de como sintaxe pode

5 Agradeço o revisor deste artigo por essa observação. 
tornar legível, pelos sistemas concepto-intencionais, a informação semântica de eventos plurais, com realizações morfológicas variadas nas diversas línguas, que satisfaz as exigências de distributividade dos sintagmas introduzidos por cada?

Conforme apresentado acima, a interpretação distributiva é dependente das relações de escopo contraídas por sintagmas quantificados dentro da sentença. Movimento em Forma Lógica para uma posição a partir da qual o constituinte funcionando como distribuidor tem escopo sobre o constituinte funcionando como parte distribuída é, a meu ver, o mecanismo pelo qual a sintaxe torna essa informação disponível para os componentes externos à faculdade da linguagem.

E-mail: evnegrao@usp.br

\section{REFERÊNCIAS BibLIOGRÁFICAS}

Aoun, J. \& Y. A., LI. 1993. Syntax of scope. Cambridge, Mass: MIT Press. Beghell, F. 1995. The phrase structure of quantifier scope. Ph.D. dissertation, University of California, Los Angeles.

Beghelli, F. 1997. Distributivity and pair-list readings. In: A. SzABolcsi (ed.) Ways of scope taking. Dordrecht, Kluwer. 349-408.

\& T. STOwell. 1997. Distributivity and negation: The syntax of 'each' and 'every'. In: A. Szabolcsi (ed.) Ways of scope taking. Dordrecht, Kluwer. 71-109.

Cномsкy, N. 1965. Aspects of the theory of syntax. Cambridge: MIT Press. . 1986. Knowledge of language. Its nature, origin, and use. New York:

Praeger.

.1988. Language and problems of knowledge. The Managua lectures.

Cambridge, Mass: MIT Press. . 1996. The Minimalist Program. Cambridge, Mass: MIT Press. 1998. Minimalist inquires: The framework. Ms., MIT, Cambridge. 2002. On nature and language. Cambridge: Cambridge University Press.

Choe, J.-W. 1987. Anti-quantifiers and a theory of distributivity. Ph.D. dissertation, University of Massachusetts, Amherst. 
Davidson, D. 1980 The logical form of action sentences. In: Essays on action and events. Oxford, Clarendon Press. 105-148.

Gomes, A. P. Q. 2004. 'Todo', 'cada' e 'qualquer': Exigências sobre a denotação nominal e verbal. Dissertação de Mestrado, USP.

HeIm, I.R. 1982. The semantics of definite and indefinite noun phrases. Ph.D. dissertation, University of Massachusetts, Amherst.

HornsteIn, N. 1995. Logical form: from GB to minimalism. Cambridge: Blackwell.

HuAnG, C-T. J. 1982. Logical relations in Chinese and the theory of grammar. Ph.D. dissertation, Massachusetts Institute of Tecnology, Cambridge. Ilari, R. \& Geraldi, J.W. 1987. Semântica. São Paulo, Ática. (Série Princípios) Kratzer, A. 1995. Stage-level and individual-level predicates. In: G. N.Carlson \& F.J. Pelletier (ed.) The generic book. Chicago \& London, The University of Chicago Press. 125-175.

Lasersohn, P. 1995. Plurality, conjunction and events. Dordrecht: Kluwer.

LOPEs, R.E.V. 2003. Aquisição da linguagem: Novos modelos e velhas análises? Letras Hoje 38. 1: 145-166.

Matthewson, L. 2000. On distributivity and pluractionality. In: B. JACKsON \& T. MatThews (eds.) Proceedings of SALT X. Ithaca, NY: CLC Publications. 98-114.

MAY, R 1985. Logical form. Its structure and derivation. Cambridge, Mass.: MIT Press.

MiLner, J.C. 1989. Introduction à une science du langage. Paris: Seuil. . 2002. Le Périple Structural. Figures et Paradigme. Paris: Seuil.

NeGrÃo, E.V. 1997. The scopal properties of DQPs in BP. Ms., University of Califórnia, Los Angeles.

. 1999. O português brasileiro: Uma língua voltada para o discurso. Tese de Livre Docência, USP, São Paulo.

\& ViotTi, E.C. 2000. Brazilian Portuguese as a discourse-oriented language. In: M.A. Kato \& E.V. Negrão (eds.) Brazilian Portuguese and the Null Subject Parameter. Frankfurt, Editorial Vervuert/ Iberoamericana. 97-116.

2001. The scopal properties of distributive quantifier phrases in Brazilian Portuguese. In: J-Y. KIM \& A. WerLe (eds.) The proceedings of SULA. The semantics of under-represented languages in the Americas. University of Massachusetts Occasional Papers in Linguistics - 25. The Graduate Linguistics Students' Association, University of Massachusetts, Amherst. 81-85. 
2002. Distributividade e genericidade nos sintagmas introduzidos por cada e todo. Revista do GEL, no. especial: 187-205.

Szabolcsi, A. 1997. Strategies for scope taking. In: A. Szabolcsi (ed.) Ways of scope taking. Dordrecht, Kluwer. 109-147. 